\title{
Wire Guided Cannulation Facilitates Endoscopic Management of Buried Bumper Syndrome: A Novel Technique
}

\author{
Jacquelin Peck, Kaitlin Sapp ${ }^{*}$, Alexander Wilsey $^{\dagger}$, and Michael Wilsey ${ }^{*, \neq}$ \\ Department of Pediatric Anesthesia, Johns Hopkins All Children's Hospital, St. Petersburg, *Department of Pediatrics, \\ University of South Florida Morsani College of Medicine, Tampa, ${ }^{+}$Undergraduate Education, State University, \\ Tallahassee, ${ }^{\ddagger}$ Division of Pediatric Gastroenterology, Hepatology and Nutrition, Johns Hopkins All Children's Hospital, St. \\ Petersburg, FL, United States
}

\begin{abstract}
Buried bumper syndrome is a rare but potentially severe complication of percutaneous endoscopic gastrostomy tube insertion. Though this complication is uncommon, it may lead to pressure necrosis, bleeding, perforation, peritonitis, sepsis, or death. Each case of buried bumper syndrome is unique in terms of patient comorbidities and anatomic positioning of the buried bumper. For this reason, many approaches have been described in the management of buried bumper syndrome. In this case report, we describe the case of an adolescent Caucasian female who developed buried bumper syndrome three years after undergoing percutaneous endoscopic gastrostomy insertion. We review diagnosis and management of buried bumper syndrome and describe a novel technique for bumper removal in which we use a guide wire in combination with external traction to maintain a patent gastrostomy lumen while removing the internal percutaneous endoscopic gastrostomy bumper.
\end{abstract}

Key Words: Endoscopy, Pediatrics, Gastroenterology

\section{INTRODUCTION}

Buried bumper syndrome (BBS) is a rare but serious complication of percutaneous endoscopic gastrostomy (PEG) tube insertion. This potentially fatal complication occurs in nearly $1 \%$ of patients receiving a PEG, and usually develops months to years after initial placement [1]. Symptoms described in association with BBS include the inability to manually insert or push the PEG tube into the gastric lumen, loss of patency, and abdominal pain. Because of the relative rarity and unique nature of individual cases of BBS, treatment modalities are often complex. Several techniques have been described within recent literature. Choice of technique depends upon patient stability and the depth and location of the internal bumper within the lamina muscularis propria of the stomach, which can be determined endoscopi-

Received : February 28, 2018, Revised : May 10, 2018, Accepted : May 19, 2018

Corresponding author: Jacquelin Peck, Department of Pediatric Anesthesia, Johns Hopkins All Children's Hospital, 5016 th street S, St. Petersburg 33705, FL, USA. Tel: +1-727-822-4300, Fax: +1-727-456-1399, E-mail: jeepeck@gmail.com

Copyright (c) 2019 by The Korean Society of Pediatric Gastroenterology, Hepatology and Nutrition

This is an open-access article distributed under the terms of the Creative Commons Attribution Non-Commercial License (http://creativecommons.org/licenses/by-nc/4.0/) which permits unrestricted non-commercial use, distribution, and reproduction in any medium, provided the original work is properly cited. 
cally or via ultrasound [1]. If the internal bumper is retained within the stomach but completely embedded, endoscopic dissection is needed. If the internal bumper has eroded into the extragastric abdomen, surgical repair is needed.

We report the case of a 15-year-old female presenting with BBS. After careful endoscopic evaluation of the bumper, we describe a novel extraction technique using external traction after passing a guidewire to maintain a patent fistula lumen. The technique was feasible for our specific patient, and allowed us to maintain a patent fistula lumen while minimizing trauma to the gastric mucosa.

\section{CASE REPORT}

A 15-year-old Caucasian female with developmental delay, dysphagia, and feeding difficulties presented 3 years after initial PEG tube placement with chief complaints of difficulty flushing the PEG tube and localized PEG-tube site pain. Upon initial physical exam, an external bulge was noted at the gastrostomy site and there appeared to be external migration of the PEG tube. BBS was suspected after considering these findings. An esophagogastroduodenoscopy then endoscopically revealed a bulge at the

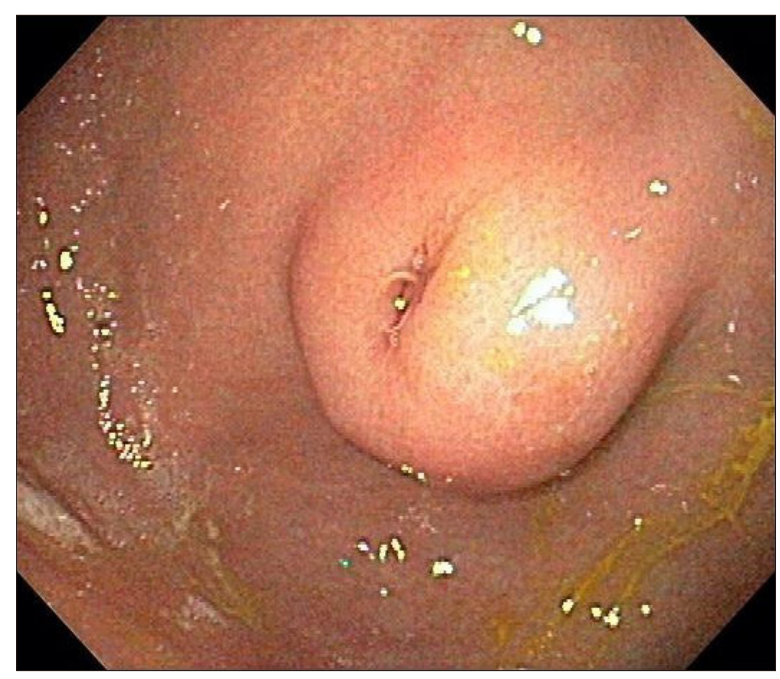

Fig. 1. Endoscopic bulge identified at percutaneous endoscopic gastrostomy tube site within the stomach. fistula site, which was identified as the internal bumper embedded within the fistula tract but maintained within the gastric lumen (Fig. 1). The external portion of PEG tube was then cut and removed near the level of the skin, allowing passage of an 0.025-inch Jagwire ${ }^{\mathrm{TM}}$ straight tip, stiff shaft, high performance guidewire (Boston Scientific, Marlborough, MA, USA) through the foreshortened PEG tube in a retrograde fashion into the stomach lumen (Fig. 2). This technique allowed cannulation of the fistula track from an external approach, thereby preserving fistula patency. External traction was applied to remove the buried PEG tube without complication, and a 14 F, 1.7-cm Mic-Key ${ }^{\mathrm{R}}$ button (Halyard Health, Alpharetta, GA, USA) was successfully placed over the guidewire. A kidney, ureter, and bladder X-ray (KUB) revealed no free air, and the patient was discharged home without complications.

\section{DISCUSSION}

PEG tube insertions are a common endoscopic procedure performed to supply or supplement the nutritional and caloric needs of patients with a wide variety of diagnoses. Although this procedure is gen-

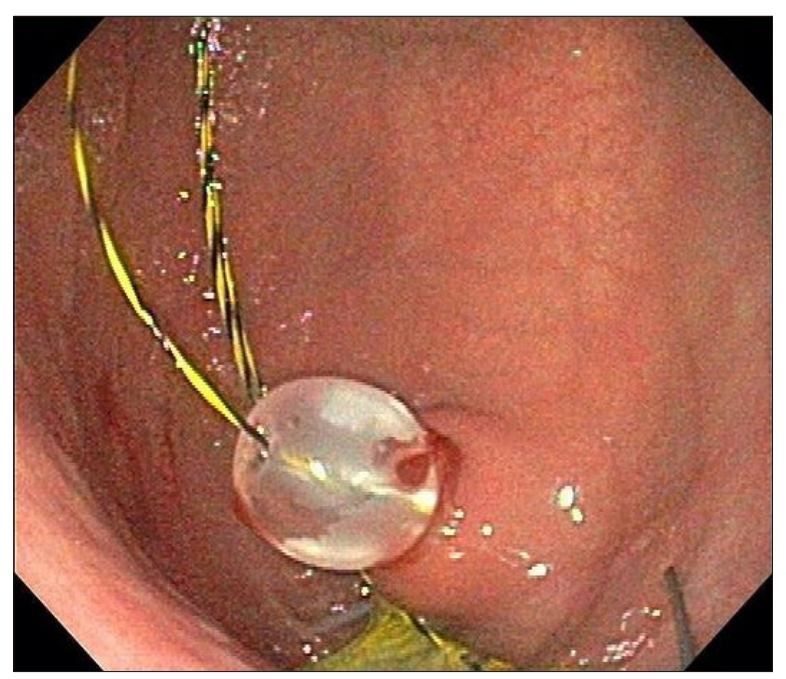

Fig. 2. Guidewire successfully passed through existing percutaneous endoscopic gastrostomy tube from an external approach, allowing subsequent gastrostomy button placement. 
erally considered low risk, it is associated with several well documented complications, which are classified as either major or minor. Reported overall complication rates vary, but affect roughly $22.5 \%$ of cases [1]. Fortunately, minor complications such as gastrostomy tube leak or obstruction are more common than major complications. Major complications are uncommon but potentially severe and include aspiration, hemorrhage, site infections, peritonitis, necrotizing fasciitis, gastrocolocutaneous fistula, unintended PEG tube removal, and BBS.

Typical manifestations of BBS include leakage, blockage, immovable tube, abdominal pain, or local erythema but may also include pressure necrosis, bleeding, perforation, peritonitis, or signs of sepsis [2]. The root of BBS is multifactorial but most strongly associated with excessive tension on the internal bumper, which causes the bumper to erode into the mucosa of the gastric lining. Significant risk factors also include receiving a percutaneous endoscopic transgastric jejunostomy and requiring two or more gastrostomy incisions [3]. Prevention is best achieved with appropriate positioning of the external bumper and maintaining regular follow-up.

Because BBS is an uncommon complication and each incidence is somewhat unique, a variety of management techniques have been described. These approaches include parallel incision and replacement of a second PEG through a new adjacent tract with surgical removal of buried bumper. Balloon replacement has also been used with the benefit of salvage of the existing PEG tube site, though this technique frequently requires dilation of fistula prior to placement of new tube, increasing trauma to an already damaged tract. Additional reports also describe extraction via external traction, bougie, grasp, needle-knife and minimally invasive push method using a papillotome [4-6].

Pre-procedural gastroscopy is indicated to confirm diagnosis and identify the depth and location of the bumper in all cases of suspected BBS unless contraindicated due to patient instability or severity of comorbidities [1]. Our patient's endoscopy revealed a bumper embedded within the gastric mucosa at the site of the fistula tract. Because this case of BBS was relatively superficial, our team of physicians elected to attempt to remove the PEG bumper with external traction after securing the lumen of the gastrostomy tract. This is a novel technique, not yet described in medical literature. With this maneuver and were able to spare the patient extensive endoscopic dissection, surgical removal, and a second gastrostomy incision for relocation of the PEG to a new site, all of which would have increased trauma to the gastric mucosa would have increased our patient's risk for a future recurrence of BBS [3].

BBS is a rare complication of PEG tube insertion. It is most commonly caused by excessive tension on the internal bumper of the PEG and may lead to severe outcomes including peritonitis, intraabdominal or gastric abscess formation, sepsis, and death. Each case of BBS is somewhat unique in terms of patient comorbidities and the positioning and location of the buried bumper. As a result, many unique techniques have been described and careful patient selection is crucial for each method. In this care report of a 15-year-old female presenting with BBS, we describe the successful treatment of BBS with careful endoscopic evaluation to assess the location and depth of the bumper, followed by extraction via external traction after passing a guidewire to maintain a patent fistula lumen. A follow up KUB confirmed the absence of intraperitoneal air and we safely discharged the patient.

\section{REFERENCES}

1. Cyrany J, Rejchrt S, Kopacova M, Bures J. Buried bumper syndrome: A complication of percutaneous endoscopic gastrostomy. World J Gastroenterol 2016;22:618-27.

2. Afifi I, Zarour A, Al-Hassani A, Peralta R, El-Menyar A, Al-Thani $\mathrm{H}$. The challenging buried bumper syndrome after percutaneous endoscopic gastrostomy. Case Rep Gastroenterol 2016;10:224-32.

3. Stewart CE, Mutalib M, Pradhan A, Bassett C, Drake D, Upadhyaya M. Short article: Buried bumper syndrome in children: incidence and risk factors. Eur J Gastroenterol Hepatol 2017;29:181-4.

4. Benatta MA. The buried bumper syndrome: external 
bumper extraction after radial mini incisions and replacement through an adjacent tract. Case Rep Med 2016;2016:5379291.

5. Mueller-Gerbes D, Hartmann B, Lima JP, de Lemos Bonotto M, Merbach C, Dormann A, et al. Comparison of removal techniques in the management of buried bumper syndrome: a retrospective cohort study of 82 patients. Endosc Int Open 2017;5:E603-7.

6. Christiaens P, Bossuyt P, Cuyle PJ, Moons V, Van Olmen A. Buried bumper syndrome: single-step endoscopic management and replacement. Gastrointest Endosc 2014;80:336. 